\title{
Heteroleptic Metallosupramolecular Complexes of Bodipy Dyes as Energy Transfer Cassettes
}

2012

Vol. 14, No. 20 5286-5289

\author{
Fazli Sozmen, ${ }^{\dagger, \ddagger}$ Birsen S. Oksal, ${ }^{\dagger}$ O. Altan Bozdemir, ${ }^{\S}$ Onur Buyukcakir, ${ }^{\ddagger}$ and \\ Engin U. Akkaya ${ }^{*, \neq, \|}$
}

Department of Chemistry, Akdeniz University, 07058 Antalya, Turkey, UNAM-Institute of Materials Science and Nanotechnology, Bilkent University, Ankara 06800, Turkey, Department of Chemistry, Ataturk University, Erzurum 25240, Turkey, and Department of Chemistry, Bilkent University, Ankara 06800, Turkey

eua@fen.bilkent.edu.tr

Received September 4, 2012

\section{ABSTRACT}

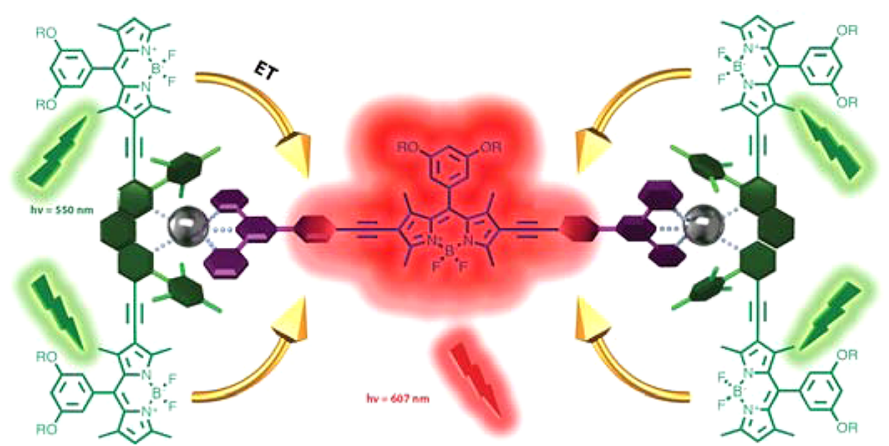

Bodipy dyes with integral phenanthroline and terpyridine units heteroleptically assemble in the presence of zinc(II) ions to form energy transfer cassettes. These discrete complexes exhibit an approach to modularly designed efficient energy transfer and light harvesting systems through metal ion coordination.

Metal ion directed assembly of organic modules en route to higher functions is an attractive field of study. ${ }^{1}$ Inherent reversibility of these assemblies is an additional bonus, providing exciting possibilities such as self-correction. ${ }^{2}$ A number of polymeric structures have been already reported, some with pendant or integral chromophores or fluorophores. ${ }^{3}$ The interaction of metal ions with the

\footnotetext{
Akdeniz University.

UNAM-Institute of Materials Science and Nanotechnology, Bilkent University.

${ }^{\S}$ Ataturk University.

"Department of Chemistry, Bilkent University.

(1) (a) Bozdemir, O. A.; Buyukcakir, O.; Akkaya, E. U. Chem.-Eur. J. 2009, 15, 3830-3838. (b) Mahata, K.; Saha, L. M.; Schmittel, M. J. Am. Chem. Soc. 2010, 132, 15933-15935.

(2) Palma, C. A.; Samori, P.; Cecchini, M. J. Am. Chem. Soc. 2010, 132, 17880-17885.

(3) (a) Fan, F.; Saha, L. M.; Song, B.; Schönherr, H.; Schmittel, M. J. Am. Chem. Soc. 2012, 134, 150-153. (b) Iehl, J.; Nierengarten, J. -F.; Harriman, A.; Bura, T.; Ziessel, R. J. Am. Chem. Soc. 2012, 134, 988998.
}

ligands yield a path for controlling spectroscopic properties of the chromophore through mechanisms such as $\mathrm{PeT}^{4}$ and ICT, ${ }^{5}$ of which some have yet to be explored. Energy funnels, energy transfer cassettes, or light harvesters define more or less the same kind of molecular assemblies, perhaps with varying degrees of complexity. ${ }^{6}$ The energy transfer process itself can be either through space (Förster type) or through bonds (Dexter type). ${ }^{7}$ The ultimate goals

(4) (a) de Silva, A. P.; McClenaghan, N. D. J. Am. Chem. Soc. 2000, 122, 3965-3966. (b) de Silva, A. P.; Gunaratne, H. Q. N.; Gunnlaugsson, T.; Huxley, A. J. M.; Rademacher, C. P.; Rice, T. E. Chem. Rev. 1997, 97, 1515-1566. (c) de Silva, A. P.; Gunaratne, H. Q. N.; Sandanayake, K. R. A. S. Tetrahedron Lett. 1990, 31, 5193-5196.

(5) (a) Bourson, J.; Valeur, B. J. Phys. Chem. 1989, 93, 3871-3876. (b) Oguz, U.; Akkaya, E. U. Tetrahedron Lett. 1998, 39, 5857-5860.

(6) (a) Ziessel, R.; Harriman, A. Chem. Commun. 2011, 47, 611-631. (b) Lin, W.; Yuan, L.; Cao, Z.; Feng, Y.; Song, J. Angew. Chem., Int Ed. 2010, 49, 375-379. (c) Rao, K. V.; Datta, K. K. R.; Eswaramoorthy, M.; George, S. Chem.-Eur. J. 2012, 18, 2184-2194.

(7) (a) Dexter, D. L. J. Chem. Phys. 1953, 21, 836-850. (b) Förster, T. Discuss. Faraday Soc. 1959, 27, 7-17. 
of such systems, besides obtaining large pseudo-Stokes shift chromophore dyads or triads, are mimicking parts of the photosynthetic process and concentrating solar radiation at a single region of the spectrum. ${ }^{8}$ Potential benefits can be significant, considering a much reduced area for the required photovoltaic device.

Bodipy dyes ${ }^{9}$ with their remarkably rich chemistry ${ }^{10}$ appeared in many dendritic and supramolecular assemblies. ${ }^{8 b, 11}$ However, energy transfer in a metallosupramolecular system was not reported. Needless to say, metal ion guided assembly of different functional units in a supramolecular device is an intriguing possibility.
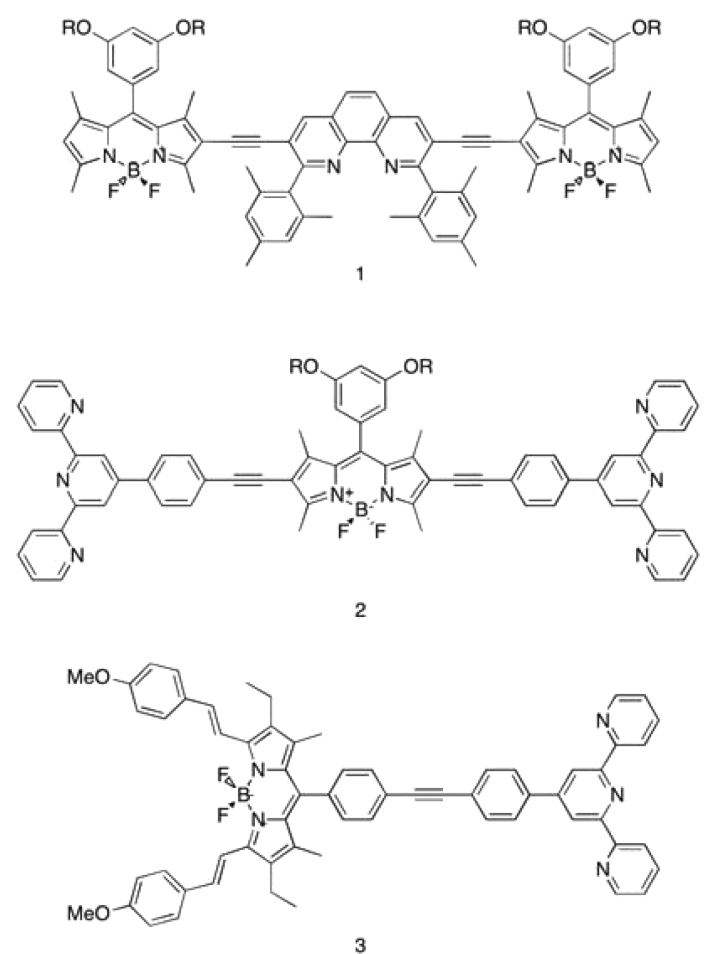

Figure 1. Ligands targeted for synthesis. R denotes decyl substituents.

In this work, our aim was to bring together Bodipy units with different absorption-emission characteristics in close proximity in order to enhance Förster-type through space energy transfer. Once appropriate and complementary modules are obtained, it would be just a straightforward

(8) (a) Currie, M. J.; Mapel, J. K.; Heidel, T. D.; Goffri, S.; Baldo, M. A. Science 2008, 321, 226-228. (b) Bozdemir, O. A.; Cakmak, S. E.; Ekiz, O. O.; Dana, A.; Akkaya, E. U. Angew. Chem., Int. Ed. 2011, 50, 10907-10912.

(9) Treibs, A.; Kreuzer, F.-H. Justus Liebigs Ann. Chem. 1968, 718, 208-223.

(10) (a) Buyukcakir, O.; Bozdemir, O. A.; Kolemen, S.; Erbas, S.; Akkaya, E. U. Org. Lett. 2009, 11, 4644-4647. (b) Bozdemir, O. A.; Cakmak, Y.; Sozmen, F.; Ozdemir, T.; Siemiarczuk, A.; Akkaya, E. U. Chem.-Eur. J. 2010, 16, 6346-6351. (c) Thivierge, C.; Aurore Loudet, A.; Burgess, K. Macromolecules 2011, 44, 4012-4015. (d) Kostereli, Z.; Ozdemir, T.; Buyukcakir, O.; Akkaya, E. U. Org. Lett. 2012, 12, 36363639.

(11) Bozdemir, O. A.; Yilmaz, M. D.; Buyukcakir, O.; Siemiarczuk, A.; Tutas, M.; Akkaya, E. U. New J. Chem. 2010, 34, 151-155. "mix-and-match" in bringing together these modules for efficient energy transfer and light harvesting.

The ligands used in this study are shown below in Figure 1. Ligands $\mathbf{1}$ and $\mathbf{3}$ were synthesized by Sonogashira couplings of appropriately functionalized precursors (Supporting Information). Ligand $\mathbf{2}$ was reported previously by our group. ${ }^{1 \text { a }}$ In order to improve solubility in organic solvents, the 8-position of the Bodipy dyes carry a 3,5-didecyloxyphenyl substituent.

Terpyridyl and phenanthrolines are good ligands for many transition metals. $\mathrm{Zn}(\mathrm{II})$ forms hexa- or pentacoordinate complexes with these ligands. Previous work has established $^{12}$ that to ensure heteroleptic coordination, one of the ligands should have bulky substituents near the donor atoms to block homoleptic coordination. To further reduce the chances of homoleptic interaction, the order of addition of ligands can be arranged as needed.

The $\mathrm{Zn}$ (II) complex of the ligand $\mathbf{1}$ was prepared by simply dissolving the ligand in a $80: 20 \mathrm{CDCl}_{3} / \mathrm{CD}_{3} \mathrm{OD}$ mixture and then refluxing in the presence of 1 molar equiv of zinc triflate. The complex structure (Figure 2) and the stoichiometry were confirmed by ESI-mass and ${ }^{1} \mathrm{H}$ NMR studies (Supporting Information).

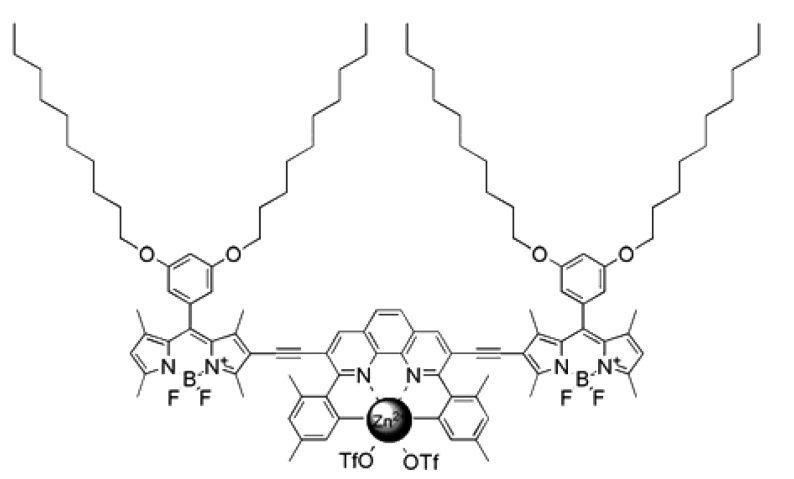

Figure 2. Structure of $1-\mathrm{Zn}(\mathrm{II})$ complex.

Ligand 2 and the $\mathrm{Zn}(\mathrm{II})$ complex of $\mathbf{1}$ were brought together by the displacement of weakly coordinating triflate ligands. The components were heated under reflux in a $80: 20 \mathrm{CDCl}_{3} / \mathrm{CD}_{3} \mathrm{OD}$ mixture, and the progress of the reaction to form the heteroleptic 1-Zn(II)-2-Zn(II)-1 (Figure 3) was followed by ${ }^{1} \mathrm{H}$ NMR. Similarly, another heteroleptic complex of ligand $\mathbf{3}$ and the $\mathrm{Zn}$ (II) complex of $\mathbf{1}$ were prepared with the 1-Zn(II)-3 arrangement (Figure 4).

In these two heteroleptic complexes, the energy donor Bodipy dyes are the same, the 2-substituted Bodipy derivative with an emission maximum of $550 \mathrm{~nm}$. Ligand 1 carries two of these donor or antenna chromophores. Thus, in the first heteroleptic complex there are a total of four donor chromophores (Figure 3). The central ligand carries one longer wavelength absorbing 2,6-disubstituted Bodipy

(12) Schmittel, M.; Kalsani, V.; Mal, P.; Bats, J. W. Inorg. Chem. 2006, 45, 6370-6377. 


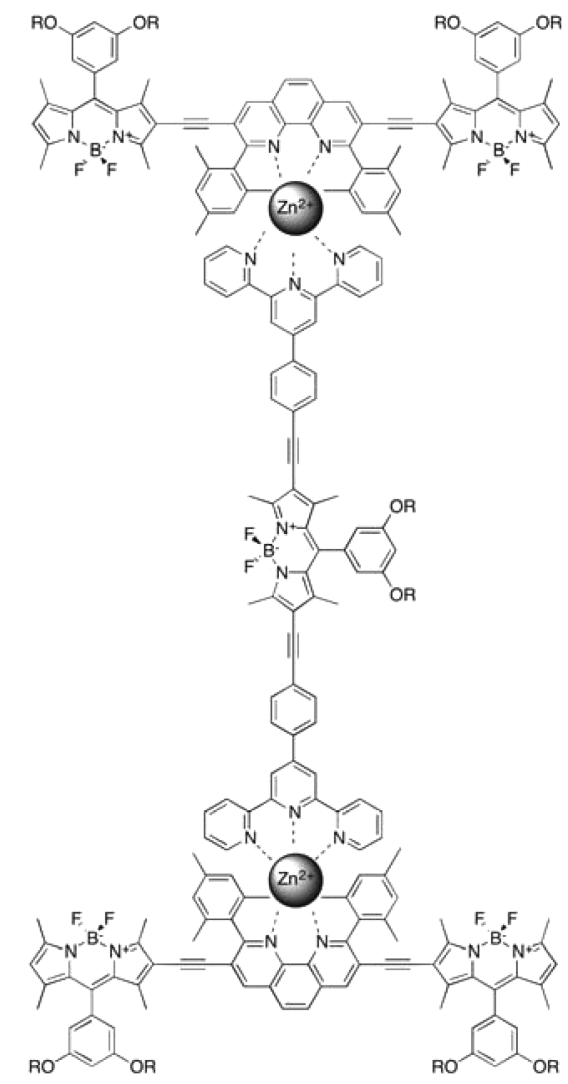

Figure 3. Structure of heteroleptic 1-Zn(II)-2-Zn(II)-1 complex.

derivative, with an absorption maximum of $575 \mathrm{~nm}$ and an emission maximum of $607 \mathrm{~nm}$. Naturally, the spectral overlap is large.

The other heteroleptic complex (Figure 4) was prepared in order to test the limits of spectral overlap, as in this complex the energy acceptor chromophore has an absorption peak at $650 \mathrm{~nm}$. Thus, in this complex the donor emission $\left(\lambda_{\max } 563 \mathrm{~nm}\right)$ and the acceptor absorption bands are separated, reducing the spectral overlap between the two types of chromophores.

Absorption spectra (Figure 5) of the complex 1-Zn(II)2- $\mathrm{Zn}(\mathrm{II})-\mathbf{1}$ and the components were acquired in $\mathrm{CHCl}_{3}-$ $\mathrm{MeOH}(8 / 2)$. Considering the extinction coefficients of the building blocks, it is not suprising that, in the heteroleptic complex, the energy acceptor core Bodipy absorption band appears as a shoulder at the same region as the free acceptor chromophore at the same concentration. Based on the emission data (Figure 6) an energy transfer efficiency of $82 \%$ can be calculated considering the changes in the donor emission.

On the other hand, absorption spectra of the 1-Zn(II)-3 complex (Figure 7) seems to be the simple sum of the absorptions of the two contributing chromophores, as expected. Emission spectra reveal the extent of energy transfer: In the first complex (1-Zn(II)-2-Zn(II)-1, Figure 3), when excited at the donor chromophore's absorption maximum, the emission intensity from the Bodipy donors drop

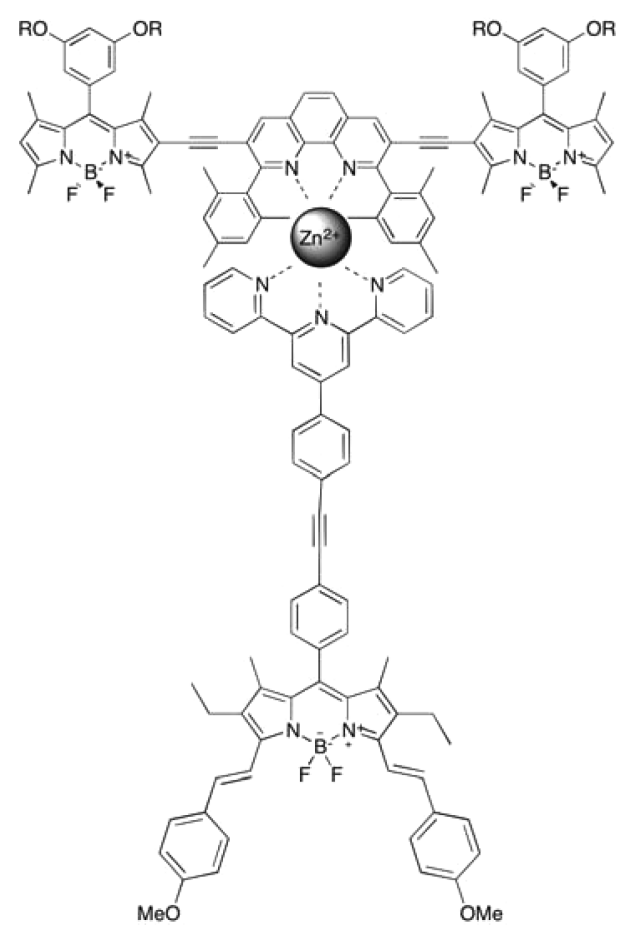

Figure 4. Structure of heteroleptic 1-Zn(II)-3 complex.

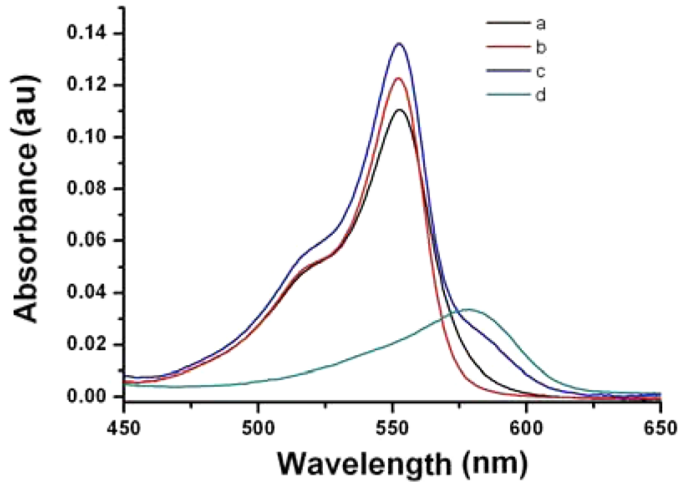

Figure 5. Absorbance spectra of 1-Zn(II)-2-Zn(II)-1 heteroleptic complex: (a) $1.0 \times 10^{-6} \mathrm{M}$ free donor 1 , (b) $1.0 \times 10^{-6} \mathrm{M}$ 1-Zn(II) complex, (c) $0.5 \times 10^{-6} \mathrm{M} 1-\mathrm{Zn}$ (II)-2-Zn(II)-1 heteroleptic complex, and (d) $0.5 \times 10^{-6} \mathrm{M}$ free acceptor 2 . The solvent was $\mathrm{CHCl}_{3}-\mathrm{MeOH}(8 / 2)$.

to one-fifth of the intensity of the free Bodipy complex at the same concentration.

Concomitantly the emission at the long wavelength band increases $70 \%$ compared to the acceptor chromophore excited at the donor absorption peak $(550 \mathrm{~nm})$.

In the 1:1 complex described above, even though the donor and acceptor peaks are somewhat separated, energy transfer upon formation of the heteroleptic complex is clearly evident. The emission "leak" in the form of emission from the energy donor Bodipy is only $20 \%$. In other 


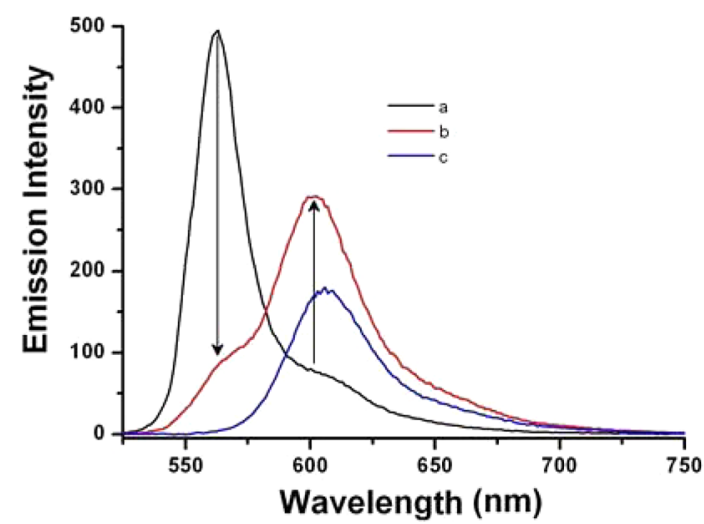

Figure 6. Emission spectral data showing the formation of 1-Zn(II)-2-Zn(II)-1 heteroleptic complex: (a) $1.0 \times 10^{-6} \mathrm{M}$ 1-Zn(II) complex, (b) $0.5 \times 10^{-6}$ M 1-Zn(II)-2-Zn(II)-1 heteroleptic complex, and (c) $0.5 \times 10^{-6} \mathrm{M}$ free acceptor 2 . Excitation was at $550 \mathrm{~nm}$, and the solvent was $\mathrm{CHCl}_{3}-\mathrm{MeOH}(8 / 2)$.

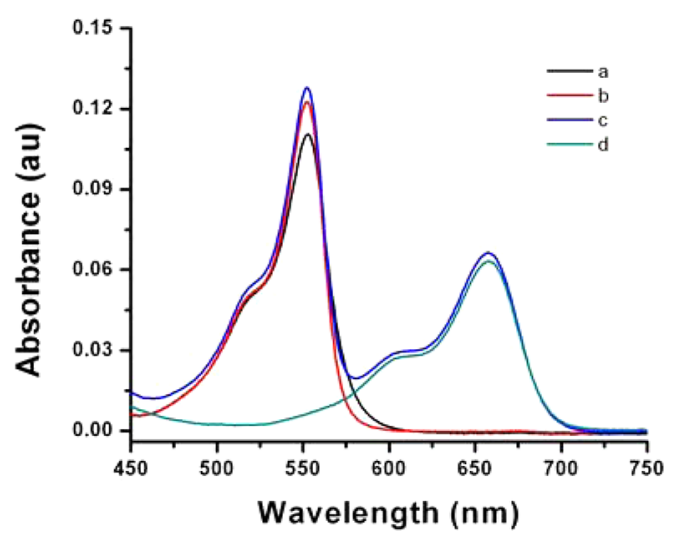

Figure 7. Absorbance spectra of 1-Zn(II)-3 heteroleptic complex: (a) free donor 1, (b) 1-Zn(II) complex, (c) 1-Zn(II)-3 heteroleptic complex, and (d) free acceptor 3. Concentrations were $1.0 \times 10^{-6} \mathrm{M}$, and the solvent was $\mathrm{CHCl}_{3}-\mathrm{MeOH}(8 / 2)$.

words, heteroleptic complex formation quenches the donor emission significantly and results in $80 \%$ efficiency in energy transfer calculated on the basis of donor quenching. Moreover, the antenna effect at $675 \mathrm{~nm}$, where the acceptor emission band is located, is more than 2-fold (Figure 8).

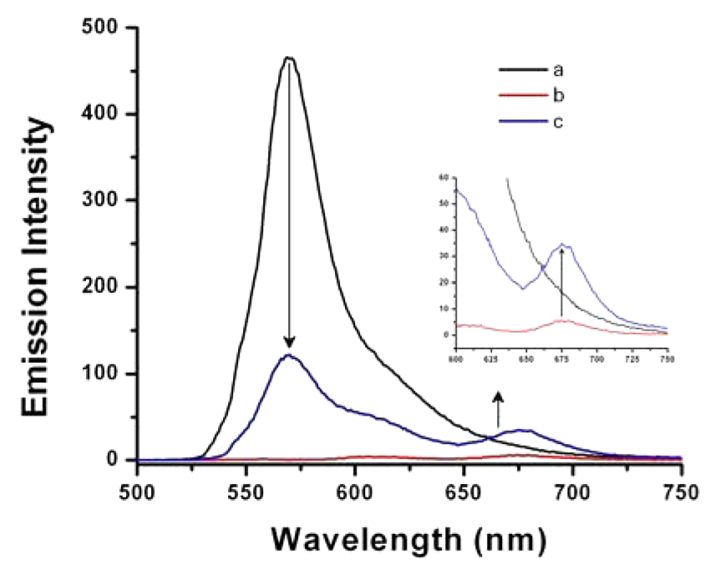

Figure 8. Emission spectral data showing the formation of 1-Zn(II)-3 heteroleptic complex: (a) $1.0 \times 10^{-6} \mathrm{M} \mathrm{1-Zn(II)}$ complex, (b) $1.0 \times 10^{-6} \mathrm{M}$ free aceptor 3 , and (c) $1.0 \times 10^{-6}$ M 1-Zn(II)-3 heteroleptic complex. Excitation was at $550 \mathrm{~nm}$, and the solvent was $\mathrm{CHCl}_{3}-\mathrm{MeOH}(8 / 2)$.

Excitation spectra for both heteroleptic complexes support energy transfer as well (Supporting Information). The role of zinc ions in directing energy transfer is clear as shown by the fact that no such spectral changes are observed when these dyes at the concentrations of this study are brought together in the absence of zinc ions.

In conclusion, we have shown that modular building blocks using metal ion directed coordination preferences can be utilized in the assembly of light harvesting complexes. The modularity can be enhanced by steric blockers reducing the chances of homoleptic interactions. Thus, multichromophoric systems with light harvesting potential can be accessed by simple procedures.

Acknowledgment. The support for this work by the Scientific Research Projects Coordination Unit of Akdeniz University is gratefully acknowledged.

Supporting Information Available. Methods, experimental procedures, additional spectral data. This material is available free of charge via the Internet at http:// pubs.acs.org.

The authors declare no competing financial interest. 